To appear in Psychology, Public Policy and Law (APA copyright) http://www.apa.org/pubs/journals/law/index.aspx

This article may not exactly replicate the final version published in the APA journal. It is not the copy of record.

Do we need to rethink guidance on repeated interviews?

David La Rooy ${ }^{1}$, Carmit Katz ${ }^{2}$, Lindsay C. Malloy ${ }^{2}, \&$ Michael E. Lamb ${ }^{2}$

${ }^{1}$ Scottish Institute for Policing Research \& University of Abertay Dundee

${ }^{2}$ University of Cambridge, UK

Running Head: $\quad$ Repeated interviews

Date Submitted: 16 November, 2009

\title{
Correspondence:
}

Professor Michael E. Lamb

Department of Social and Developmental Psychology

Faculty of Politics, Psychology, Sociology, and International Studies

University of Cambridge

Free School Lane

Cambridge CB2 3RQ

United Kingdom

E-mail:mel37@cam.ac.uk

Authors' Note: The contributions of the authors were equal.

To appear in Psychology, Public Policy and Law (APA copyright )

http://www.apa.org/pubs/journals/law/index.aspx

This article may not exactly replicate the final version published in the APA journal. It is not the copy of record. 


\begin{abstract}
Within the legal system, children are frequently interviewed about their experiences more than once, with different information elicited in different interviews. The presumed positive and negative effects of multiple interviewing have generated debate and controversy within the legal system and among researchers. Some commentators emphasise that repeated interviews foster inaccurate recall and are inherently suggestive, whereas others emphasise the benefits of allowing witnesses more than one opportunity to recall information. In this article we briefly review the literature on repeated interviewing before presenting a series of cases highlighting what happens when children are interviewed more than once for various reasons. We conclude that, when interviewers follow internationally recognised best-practice guidelines emphasising open-questions and free memory recall, alleged victims of abuse should be interviewed more than once to ensure that more complete accounts are obtained. Implications for current legal guidelines concerning repeated interviewing are discussed.
\end{abstract}


To appear in Psychology, Public Policy and Law (APA copyright) http://www.apa.org/pubs/journals/law/index.aspx

This article may not exactly replicate the final version published in the APA journal. It is not the copy of record.

Do we need to rethink guidance on repeated interviews?

Through decades of research on children's memory, suggestibility, and eyewitness capabilities, the effects of repeated interviewing have remained controversial (Bruck \& Ceci, 2004; Goodman \& Quas, 2008; La Rooy, Lamb \& Pipe, 2009; Malloy \& Quas, 2009). The controversy has been prolonged by the co-existence of two very different lines of psychological research, one focused on the beneficial and the other on the negative effects of repeated interviews (see La Rooy et al., 2009 for a review). To date, the larger body of research documenting the extent to which repeated interviewing can increase suggestibility has received the most attention, and these negative effects have been widely touted in both legal and academic circles (see Brainerd \& Reyna, 2005, p. 304; Goodman \& Quas, 2008). In particular, a failure to distinguish between the effects of repeated suggestive interviewing and the effects of repeated interviewing per se has led professional guidance, prosecutorial decision-making, and judicial fact-finding to frown on the practice of repeated interviewing (Home Office, 2007, sections 2.13, 2.117 \& 2.188; Law Commission, 1997, section 97, Scottish Executive, 2003, section 30; Scottish Executive, 2007, sections 7 \& 155), as several recent rulings attest (Commonwealth v. Baran, 2009; State v. Bodilla, 2006).

In this article, we challenge this conclusion, arguing that interviewing children more than once can be extremely valuable for a number of reasons when the interview context and the types of questions asked conform to those recommended in best-practice interview guidelines. Indeed, as we show in the cases that follow, repeated non-suggestive interviews that are dominated by open-ended questions have clear benefits. We begin by briefly reviewing the psychological research and forensic implications of repeated interviews before describing four cases illustrating the circumstances in which repeated interviewing should be recommended rather than discouraged by forensic interview guidelines. 
To appear in Psychology, Public Policy and Law (APA copyright) http://www.apa.org/pubs/journals/law/index.aspx

This article may not exactly replicate the final version published in the APA journal. It is not the copy of record.

Relevant cognitive psychological research

Many cognitive psychologists have shown a robust reminiscence effect when the ability to remember lists of words or sets of pictures is tested (e.g., Erdelyi \& Becker, 1974; Roediger \& Payne, 1982; Roediger, Payne, Gillespie \& Lean, 1982; Shapiro \& Erdelyi, 1974; for reviews see Erdelyi, 1996, and Payne, 1987). Across repeated tests separated by delays of several minutes, participants reminisce (i.e., report) new, previously unrecalled, items, suggesting that recall (as measured by a single test) is typically incomplete because there is usually more unrecalled information in memory. The reminisced information recalled using free-recall procedures in these studies is generally accurate. This reminiscence effect is perhaps the most startling and counterintuitive feature of memory where repeated interviewing is concerned; the inability to recall some specific memories at any one time is actually quite normal and we thus should not expect complete recall after a single attempt at retrieval (i.e., a single interview).

The cognitive psychological literature has also ruled out an alternative explanation of the reminiscence effect, namely that additional recall is attributable to the increased amount of recall time available rather than to repeated testing per se. By including in their study a group of participants whose recall trials were not separated by intervals, Erdelyi and Becker (1974) showed that, when given comparable amounts of recall time, the recall of new information was greatest when there were intervals between each recall test instead of a longer single test. Shapiro and Erdelyi (1974) also held recall time constant in a similar study but only provided a single recall opportunity of either 30 seconds or 5 minutes. More information was recalled in the delayed 5minute test, underscoring the conclusion that 'time' is also needed to facilitate reminiscence. The tests themselves are not merely a measure of memory, furthermore; rather, they enhance learning and memory (see Roediger \& Karpicke, 2006). 
To appear in Psychology, Public Policy and Law (APA copyright) http://www.apa.org/pubs/journals/law/index.aspx

This article may not exactly replicate the final version published in the APA journal. It is not the copy of record.

Several researchers have reported similar findings when children are studied (Brainerd, Reyna, Howe, \& Kingma, 1990; Howe \& Brainerd 1989; Howe, Kelland, BryantBrown, \& Clark, 1992). Howe et al. (1992) also found, as predicted, that there was more reminiscence due to 'retrieval (re)learning' after shorter than after longer delays, presumably because the memory traces were more likely to be intact in such circumstances. After longer delays, fewer items of new information would be available to recall because the memory traces would have decayed and would thus need to be (re)constructed. In general, therefore, the more easily retrievable or recognisable memories are, the greater the likelihood of reminiscence. Developmental differences are apparent when the level of initial encoding is held constant (i.e. the to-be-remembered (TBR) information is learned to the same criterion), with younger children forgetting more than older children (Brainerd, Reyna, Howe, \& Kingma, 1990). Interestingly, however, 7 1/2- and 10-year-old children did not differ with respect to the benefits of repeated testing (Howe et al., 1992): Although the younger children forgot more, the effects of repeated testing were the same.

\section{Applied research}

Applied studies of eyewitness memory have similarly shown that new information is reported when participants are repeatedly interviewed (Bluck, Levine, \& Laulhere, 1999; Bornstien, Liebel, \& Scarberry, 1998; Dunning \& Stern, 1992; Gilbert \& Fisher, 2006; La Rooy, Pipe \& Murray, 2005; La Rooy, Pipe \& Murray, 2007; Scrivner \& Safer, 1988). Drawing on the research findings summarised above, applied researchers have represented 'repeated interviewing' as 'repeated testing' and have also addressed important practical questions regarding the effects of recall delay, age, and suggestibility on the amount and accuracy of information recalled across repeated interviews.

When re-interviews take place soon (less than 48 hours) after the TBR events and the initial interviews, a sizeable proportion of new information (between $26 \%$ and $39 \%$ of the 
To appear in Psychology, Public Policy and Law (APA copyright) http://www.apa.org/pubs/journals/law/index.aspx

This article may not exactly replicate the final version published in the APA journal. It is not the copy of record.

total amount of information obtained) is recalled (La Rooy et al., 2005), and about $90 \%$ of the new information is accurate (Gilbert \& Fisher, 2006; La Rooy et al., 2005). For children, recall delay is an especially important consideration, however: delays of months and years make forgetting likely and the accuracy of new information decreases considerably (accuracy rates of approximately 50\%; La Rooy et al., 2007; Peterson, Moores \& White, 2001; Pipe, Gee, Wilson \& Egerton, 1999, Experiments 1 \& 2; Salmon \& Pipe, 1997, 2000; Steward et al., 1996). Poole and White (1993) found that, after a 2-year delay, children responded consistently when questions were repeated within the interview but half of their answers differed from those given two years earlier, perhaps because the children had forgotten their original answers, the event in question, or both.

Repeated interviews occurring soon after the target events may thus be the most appropriate way of obtaining more information about experienced events than children can provide in a single interview. Furthermore, repeated interviews can also serve as reminder cues, facilitate rehearsal and recall, reduce forgetting (e.g., inoculation effects), and even, at times, increase resistance to misleading suggestions or questions (Baker-Ward, Hess, \& Flannagan, 1990; Brainerd \& Ornstein, 1991; Fivush \& Schwarzmueller, 1995; Goodman, Hirschman, Hepps, \& Rudy, 1991; Gordon, Baker-Ward, \& Ornstein, 2001; La Rooy et al., 2005; Ornstein, 1995; Ornstein, Baker-Ward, Gordon, \& Merritt, 1997; Ornstein, Gordon, \& Larus, 1992). These findings are theoretically consistent with the cognitive psychology research discussed above (i.e., Howe \& Brainerd, 1989) showing that repeated interviews following shorter rather than longer delays are most likely to foster the reminiscence of new information.

However, repeated interviewing is not always associated with decreases in recall across recall delays of weeks, months, and years. Studies of stressful events, for example, frequently reveal no changes in the amounts of information recalled in initial and delayed 
To appear in Psychology, Public Policy and Law (APA copyright) http://www.apa.org/pubs/journals/law/index.aspx

This article may not exactly replicate the final version published in the APA journal. It is not the copy of record.

interviews (Ackil, Van Abbema, \& Bauer, 2003; Burgwyn-Bailes, Baker-Ward, Gordon, \& Ornstein, 2001; Herskowitz, Orbach, Lamb, Sternberg, Horowitz, \& Hovav, 1998; Merritt, Ornstein, \& Spicker, 1994), and some researchers have shown increases over time (Fivush, McDermott Sales, Goldberg, Bahrick \& Parker, 2004; Peterson, Pardy, Tizzard-Drover, \& Warren, 2005). Perhaps the stressful events studied were more salient and thus more memorable. In addition, because the events were salient, the children may have recalled or been reminded of them frequently, thus, helping to protect against forgetting (Cordon, Pipe, Sayfan, Melinder, \& Goodman, 2004; Pipe, Lamb, Orbach, \& Esplin, 2004; Pipe, Sutherland, Webster, Jones, \& La Rooy, 2004). We should, therefore, not automatically discount the advantages of repeated interviewing simply because significant amounts of time have elapsed, although the effects of delay are obviously very important.

Developmental differences may also be important, but the available literature remains inconclusive (see La Rooy et al., 2009 for in depth review). Several studies show no age differences across repeated interviews when the total amount recalled is measured (i.e., older children recall more information; Goodman, Hirschman, Hepps, \& Rudy, 1991; Peterson, 1996; Peterson \& Bell, 1996; Ornstein, Baker-Ward, Gordon, Pelphrey, Staneck Tyler, \& Gramzow, 2006; Pipe, Gee, Wilson, Egerton, 1999; Powell \& Thomson, 1997). Some other studies show age differences across repeated interviews, but the findings are mixed, with the decreases in correct recall across repeated interviews sometimes largest for older children (Pipe et al., 1999; Salmon \& Pipe, 1997). Even studies by the same researchers have shown contrasting results with accuracy decreasing more rapidly for younger than for older children in one study (Peterson \& Whalen, 2001), but then decreasing more rapidly for older than younger children in another (Peterson, 1999). Even within single studies it is sometimes difficult to discern systematic developmental differences in the effects of repeated interviewing (Gordon \& Follmer, 1994). 
To appear in Psychology, Public Policy and Law (APA copyright) http://www.apa.org/pubs/journals/law/index.aspx

This article may not exactly replicate the final version published in the APA journal. It is not the copy of record.

When children experience repeated suggestive interviews, the effects of suggestion increase across repeated interviews (Bruck, Ceci, \& Hembrooke, 2002; Leichtman \& Ceci, 1995; Melnyk \& Bruck, 2004; Powell, Jones, \& Campbell, 2003; Principe \& Ceci, 2002) and the effects of suggestion are greater for younger as opposed to older children (Ceci, Lotfus, Leichtman, \& Bruck, 1994; Gobbo, 2000; Goodman, Hirschman, Hepps, \& Rudy, 1991; Ornstein, Gordon, \& Larus, 1992; Pipe \& Wilson, 1994). Of course, suggestibility effects emerge in the initial interviews, but repeated interviewing seems to exacerbate the problems associated with repeated interviewing.

Although, the benefits of repeated interviewing are thus undermined when the interviews are suggestive, especially when the children are very young (see La Rooy et al., 2009 for a review), this should not lead investigators to avoid repeated interviewing completely. Instead, the results described above highlight the importance of good training designed to ensure that interviewers adhere to best-practice guidelines and avoid using suggestive techniques whether conducting single or repeated interviews. Suggestive interviewing can powerfully influence children's reports even within the context of a single interview (e.g., Bruck \& Ceci, 2004; Ceci, Kulkofsky, Klemfuss, Sweeney, \& Bruck, 2007; Quas et al., 1999), and it is thus important both to distinguish between suggestive and repeated interviewing and to avoid confusing definitions of their characteristics and effects on children's reports (Quas et al., 2007). As Goodman and Quas (2008, p. 389) remark, "the simple conclusion that repeated interviews cause errors in children's reports rests on weak ground."

Forensic interviews

Unfortunately, the beneficial effects of repeated interviewing have not, thus far, been translated into best-practice guidelines for forensic interviewers. Indeed, most professional guidelines discourage repeated interviews with child witnesses and victims of crime on the 
To appear in Psychology, Public Policy and Law (APA copyright) http://www.apa.org/pubs/journals/law/index.aspx

This article may not exactly replicate the final version published in the APA journal. It is not the copy of record.

grounds that they are intrinsically suggestive, may cause witnesses to become 'inconsistent' in their recollection of events (i.e., they may reminisce additional information), may be seen as unnecessary or oppressive, or may prolong the victims' distress (see, for example, Home Office, 2007, sections 2.13, $2.117 \&$ 2.188; Law Commission, 1997, section 97; Scottish Executive, 2003, section 30; Scottish Executive, 2007, sections 7 \& 155). Nonetheless, repeated interviews are a regular feature of forensic investigations involving children. Estimates of the numbers of times children are interviewed range from an average of 4 interviews (Goodman et al., 1992; Malloy, Lyon \& Quas, 2007; Plotnikoff \& Woolfson, 2001) to an average of 11 (Ceci \& Bruck, 1993) with some cases involving as many as 25 interviews (Malloy et al., 2007).

Although interview guidelines discourage repeated interviewing, most guidelines acknowledge that it is sometimes appropriate to conduct repeated interviews (see, for example, Home Office, 2007, sections 2.117, 2.206, 2.188, 2.225; Scottish Executive, 2003, sections 30, 108; Scottish Executive, 2007, sections 328). For example, when alleged victims are too distressed, interviewers may need to build trust and rapport across interviews. Interviewers may also need to re-interview witnesses who have learning disabilities or short attention spans. In some cases, interviewers may re-interview witnesses when there are good reasons to suspect that abuse has occurred (e.g., medical examinations, suspect confessions, recording of abuse) but the victim did not disclose in the initial interview. In other cases, new information or evidence may come to light, or the allegations may be too complex to explore in a single interview. Official guidelines thus justify repeated interviews to obtain information that could not be obtained initially due to the dynamics of the interview, the child's motivations or limitations, or because that interview took place before the investigation had progressed. In such cases, the interviews might best be considered 
To appear in Psychology, Public Policy and Law (APA copyright) http://www.apa.org/pubs/journals/law/index.aspx

This article may not exactly replicate the final version published in the APA journal. It is not the copy of record.

'extended' rather than 'repeated' because different questions are likely asked about different topics in order to obtain as-full-as-possible an account of what happened.

In addition to the very practical reasons for re-interviewing alleged victims that are recognized by current legal guidelines, repeated interviewing may also be useful to capitalize on what we know about human memory and the phenomenon of reminiscence, although professional interview guidelines have not yet recognized reminiscence as a justifiable reason to conduct multiple interviews. However, a recent field study involving alleged victims of child sexual abuse documented the value of asking about the same topics or issues in second interviews (Hershkowitz \& Terner, 2007). Although children reported most forensicallyrelevant details the first time they were questioned, $14 \%$ of the details that were central to the allegations (such as the nature of the sexual contact) were only provided in a second interview 30-minutes later, as were an additional $9 \%$ of the details about the context in which the alleged events occurred (e.g., the color of the suspect's car). In a later study (Katz \& Hershkowitz, under review), a second interview conducted 7 minutes after the first yielded more than half as many (59\%) new details as the first with 50\% of the information provided in response to open-ended free recall prompts. Clearly, substantial amounts of new information can be recalled when children are re-interviewed, even after short delays, suggesting that the 'reminiscence' effect should be considered sufficient grounds for conducting repeated free recall interviews. This study included simple practical guidelines specifying that, after children had provided narrative accounts of the suspected abuse in response to open-ended prompts (e.g., "Tell me what happened"), they were given a short break or rest (7-10 minutes). After the break, interviewers, using open-ended prompts, again invited the children to describe what happened. The exclusive reliance on open-ended requests for information allowed children to disclose as many details as possible without possible contamination by the interviewers, thereby maximizing the perceived credibility of 
To appear in Psychology, Public Policy and Law (APA copyright) http://www.apa.org/pubs/journals/law/index.aspx

This article may not exactly replicate the final version published in the APA journal. It is not the copy of record.

the narratives. Following the second open-ended interview, closed questions (e.g., directive: "when did it happen?” option-posing: "did he touch you over or under the clothes?”) were used to clarify details of the alleged incident.

Illustrative cases: What happens when children are interviewed more than once?

Evidently, the information recalled in initial interviews is usually incomplete; repeated recall attempts allow new information to be retrieved from memory that was not recalled in earlier interviews. In the cases described below, we illustrate how valuable it may be to interview children (in these cases, ones who are alleging sexual abuse) more than once. These cases, involving children of varied ages and diverse circumstances, richly illustrate the benefits of conducting more than one interview and complement experimental psychological and field research. Also, these cases illustrate that a second interview can be prompted for different reasons, thus highlighting instances where legal guidelines have taken the findings of psychological research into account, and where they have yet to do so. The first two cases demonstrate reasons for conducting repeated interviews that can be easily justified with reference to published interview guidelines, whereas the second two cases show that repeated interviews can be beneficial for reasons not currently acknowledged in interview guidelines.

The cases were drawn from among 100 investigations in which the alleged victims of child sexual abuse were re-interviewed. All interviews were conducted following the NICHD Investigative Interview Protocol, a set of structured guidelines for interviewers which improves the quality of forensic interviews by helping interviewers use open-ended questions effectively and productively (Lamb, Hershkowitz, Orbach, \& Esplin, 2008; Lamb, Orbach, Hershkowitz, Esplin, \& Horowitz, 2007; Orbach et al., 2000). One of the main criticisms of field work in this area is that it is often unknown whether children are indeed victims of abuse and are therefore describing actual incidents of victimization. Of importance, in each of 
To appear in Psychology, Public Policy and Law (APA copyright) http://www.apa.org/pubs/journals/law/index.aspx

This article may not exactly replicate the final version published in the APA journal. It is not the copy of record.

the cases presented here, there was independent external evidence (e.g., suspect confession, medical findings) suggesting that the children had indeed been abused.

In presenting transcripts of these four interviews, we have (re)arranged the responses to form a single composite interview transcript in order to distinguish among information that was unique to the first interview, information unique to the second interview, information repeated in both interviews, and contradictory information, using regular, bold, $\underline{\text { underlined }}$ and CAPITALIZED fonts respectively. In these cases, the information was elicited predominantly using recall-based questions (e.g., open-ended "Tell me what happened" and direct What, When, Where questions) as opposed to focused recognition-based prompts (e.g., was that over or under your clothes?"). We have also not included utterances by the children that did not add information about what happened (e.g., "um, I am trying to remember"; "let me think").

Case 1

A 14-year-old girl disclosed to her mother that the mother's ex-partner had touched her, made her touch him, and attempted to penetrate her, and she was thus interviewed by an investigator. After the first interview, the girl told her mother that she had forgotten to mention another occasion in which she had been videotaped, so a second interview focusing on this alleged incident took place a day after the first initial interview. A composite transcript of the girl's account appears in Table 1.

\section{INSERT TABLE 1 HERE}

The girl was cooperative during the pre-substantive (rapport building and episodic memory) phase of the first interview, and disclosed abuse when the interviewer said, "My job is to talk to people about things that might have happened to them. It's important that you explain to me why you are here today." She went on to describe three different abusive episodes: the first, the last, and another that involved watching a pornographic film. The girl 
To appear in Psychology, Public Policy and Law (APA copyright) http://www.apa.org/pubs/journals/law/index.aspx

This article may not exactly replicate the final version published in the APA journal. It is not the copy of record.

disclosed most of the important details about these episodes of abuse in response to open questions. To understand more about the way that the perpetrator touched her (e.g., whether the touch was over or under her clothes), the interviewer asked a few directive questions and one option-posing question.

After returning home, the victim told her mother that she also remembered making a videotape with the perpetrator. This disclosure prompted the second interview, which took place one day after the first. In the second interview, the interviewer first reminded the girl of the interview ground rules and emphasized the importance of telling the truth. Then, following open invitations, the girl indicated why the interview was taking place and described important details about the perpetrator's attempts to penetrate her while making a videotape. Later, the interviewer asked some questions about unexplored aspects of the abusive episodes mentioned in the first interview. In response to these questions, the girl disclosed further important details about those episodes (e.g., "he asked me to go to the other room with him", "he had clothes on", "he tried to put his willy inside me", "they were having sex", "the willy was going into the fanny").

As the transcript shows, this girl provided a considerable amount of unique information in the second interview, including additional information about the incidents described in the first interview. Furthermore, the first interview appeared to have served as a reminder cue, triggering her memory of the incident involving the videotape and providing the impetus for the second interview.

Case 2

When first interviewed, this 6-year-old girl named but refused to disclose sexual abuse by her 14-year-old brother, and was uncooperative, even though their mother had witnessed an incident of the abuse. A few days later, she was abused again, however, so she asked her mother to contact the interviewer. In the second interview, the girl provided many 
To appear in Psychology, Public Policy and Law (APA copyright) http://www.apa.org/pubs/journals/law/index.aspx

This article may not exactly replicate the final version published in the APA journal. It is not the copy of record.

forensically-relevant details about three different episodes of abuse in response to open-ended questions (Table 2).

\section{INSERT TABLE 2 HERE}

This case clearly demonstrates the utility of second interviews when children are reluctant to describe their experiences in the first interview. Reluctance is relatively common among child victims of sexual abuse, particularly when there is a close victim-perpetrator relationship (Hershkowitz, Horowitz, \& Lamb, 2005). In such cases, a second interview may reduce children's unwillingness to disclose because they trust the interviewers more, feel less stressed by the context or, as in this case, because the abuse has become too intrusive and burdensome not to request help.

Case 3

This investigation was initiated when a 13-year-old girl recognised a man who had abused her in the street and subsequently reported him to the police. When apprehended, the perpetrator admitted that he had abused several girls, including the complainant, who was thus interviewed after the case had been 'solved'. The girl was later re-interviewed so that she could talk further about the abuse, thereby capitalizing on the memory phenomenon of reminiscence.

Only open questions were asked in the two interviews, which were only 10 minutes apart. The second interview began with the following invitation, "Tell me again everything that happened to you from the beginning to the end as best you can." In response, the girl gave a rich and coherent narrative regarding the alleged incident, using several sequence words (e.g., then, after, before) that helped to clarify the events first described in the initial interview. A few directive questions were asked at the end of the second interview to confirm details about the suspect's appearance. The composite narrative appears in Table 3.

INSERT TABLE 3 HERE 
To appear in Psychology, Public Policy and Law (APA copyright) http://www.apa.org/pubs/journals/law/index.aspx

This article may not exactly replicate the final version published in the APA journal. It is not the copy of record.

Although the important details were repeated in both interviews, some of the additional information provided in the second interview was central to the incident and was more specific with respect to time (e.g., "a month ago"), perpetrator actions (e.g., "he pulled me and grabbed me in my vagina and bottom", "he caught my body like this"), location of the victim and perpetrator during the incident (e.g., "suddenly I saw him in the entrance of my building", "I was far from the mailboxes"), victim sensory reactions (e.g., "my whole body shivered", "I felt unbearable pain") and descriptions of specific body parts involved in the incident (e.g., "with two fingers in my private place", "it was deep"). Some details were nonetheless omitted from the second interview (e.g., the girl's feelings and thoughts). This highlights the importance of considering accounts provided in both interviews when seeking a more complete understanding of what happened.

\section{Case 4}

The final case example involved a 5-year-old boy who, as in case 3, was reinterviewed after a short break to also capitalise on the phenomenon of reminiscence. As the composite transcript (Table 4) reveals, the second retrieval yielded details concerning sequence (e.g., "then took some leaves"), perpetrator actions (e.g., "he took off his trousers and underwear"), location of the victim and perpetrator (e.g., "he met me outside my house"), victim sensory reactions (e.g., "it was very painful"), and specific body parts (e.g., "he bit my penis"). Again, this case highlights the importance of combining information obtained in the two interviews to construct the most complete account of what happened.

\section{INSERT TABLE 4 HERE}

\section{Discussion}

The composites created from repeated interviews of four children provide compelling evidence as to why it can be valuable to interview alleged victims more than once. The first two cases document the value of repeated interviewing when there are practical reasons for 
To appear in Psychology, Public Policy and Law (APA copyright) http://www.apa.org/pubs/journals/law/index.aspx

This article may not exactly replicate the final version published in the APA journal. It is not the copy of record.

conducting the second interview and would be easily justified with reference to existing bestpractice interview guidelines. The second two cases show how repeated interviews can facilitate reminiscence when the same topics are discussed in a second interview. The latter two cases are particularly important for showing both how the results of experimental research concerning repeated interviews are relevant in forensic contexts and how single interviews are unlikely to yield complete accounts of remembered events. In each case, it is clear that repeated interviewing was investigatively valuable. However, in the latter two cases (3 and 4), multiple interviews would not have been justified by current legal guidelines and current recommended best practices guidelines.

Regardless of the reasons why the children were re-interviewed, both young children and adolescents provided new information that would be helpful for investigators (e.g., location of corroborative evidence, detailed description of abusive incidents, abuse severity). Furthermore, there were no contradictions between the details provided in the two interviews. Although the accuracy of the children's reports cannot be judged because we were studying field interviews rather than reports of staged events, it is important to note that the cases discussed here were corroborated by suspect confessions, eyewitness accounts, or medical evidence, reducing the likelihood that the allegations were false.

Certainly, the cases described here do not represent all situations in which repeated interviews with child witnesses might be considered. Nonetheless, the findings are consistent with what we would expect based on psychological research examining the advantages of repeated interviewing. Because open-ended questions were used and none of the interviews included the types of suggestive questions which are commonly linked to false reports (Bruck et al., 2002; Ceci, Huffman, Smith, \& Loftus, 1994; La Rooy et al., 2009), there is good reason to treat the information provided as credible, particularly because all allegations were corroborated in some way (see above). Also, decades of research demonstrates that details 
To appear in Psychology, Public Policy and Law (APA copyright) http://www.apa.org/pubs/journals/law/index.aspx

This article may not exactly replicate the final version published in the APA journal. It is not the copy of record.

elicited using recall or open-ended prompts are more likely to be accurate than details elicited using more focused prompts in both field and laboratory analogue contexts (Dale, Loftus, \& Rathbun, 1978; Dent, 1986; Dent \& Stephenson, 1979; Goodman, Bottoms, SchwartzKenney, \& Rudy, 1991; Hutcheson, Baxter, Telfer, \& Warden, 1995; Lamb \& Fauchier, 2001; Lamb, Orbach, Hershkowitz, Horowitz, \& Abbott, 2007; Orbach \& Lamb, 2001).

Indeed, there was no evidence that repeated interviewing prompted inaccuracy, as commonly assumed. Stated differently, suggestive questioning and interviewer bias are bad in either single or repeated interviews, as demonstrated in a number of infamous 'multivictim' cases, including the McMartin, Fells Acres, Little Rascals, and Newcastle Crèche cases and in scientific research concerning objectively verifiable events (e.g., Quas et al., 1999; Quas et al., 2007). However, that should not lead us to overlook the potential value of multiple non-suggestive interviews. Broad generalized statements about the harmful effects of repeated interviews are clearly unwarranted although often made by academics, practitioners, jurists, and policy makers alike.

In addition to cognitive processes (e.g., reminiscence), repeated interviews using open-ended questions may help children overcome the emotional difficulties and stresses often associated with forensic interviews about sexual abuse (Goodman et al., 1992). Children who have close relationships with perpetrators may find it especially difficult to disclose (Pipe, Lamb, Orbach, \& Cederborg, 2007) and, in such cases, it is critical for interviewers to create trusting relationships with alleged victims. This may be difficult to achieve in only one interview, while repeated interviews may help some children feel more comfortable (Carnes, Nelson-Gardell, Wilson, \& Orgassa, 2001; Carnes, Wilson, \& NelsonGardell, 1999). However, it is also important to realise that repeated interviews may be very distressing for some children because they are being asked to 'relive' and discuss painful 
To appear in Psychology, Public Policy and Law (APA copyright) http://www.apa.org/pubs/journals/law/index.aspx

This article may not exactly replicate the final version published in the APA journal. It is not the copy of record.

memories and experiences. Investigators, in collaboration with mental-health professionals, must balance the immediate needs of the children with the need to advance investigations.

Although psychologists know a great deal about the beneficial effects of repeated interviewing, this knowledge seems to have had limited impact on either professional guidelines or practices. This may be related to the "bad reputation" of repeated interviews following the infamous 1980s day-care child sexual abuse cases in which multiple, suggestive interviews were the norm. It may also be attributable, in part, to fears that children may contradict themselves, thereby casting doubt on their perceived credibility. In legal and forensic contexts, consistency is often viewed as an indicator of veracity or credibility (Berliner \& Conte, 1993; Leippe, Romancyzk, \& Manion, 1992; Raskin \& Esplin, 1991). In Quas et al.’s (Quas, Thompson, \& Clarke-Stewart, 2005) survey concerning beliefs about child witnesses, for example, almost one-third (29\%) of jurors agreed with the statement, "Inconsistencies in a child's report of sexual abuse indicate that the report is false." However, inconsistencies should be distinguished from contradictions as we have shown in the cases reported in this article. It may be difficult for investigators to recognise that inconsistencies, in the form of new details emerging in later interviews, are entirely normal features of memory (Fivush \& Shukat, 1995), even during descriptions of abusive events (Ghetti, Goodman, Eisen, Qin, \& Davis, 2002). When open-ended questions are repeated, children tend to report many new (but nonetheless accurate) details about known events (Fivush, Hamond, \& Harsch, 1991; Hamond \& Fivush, 1991; Peterson et al., 2001), and the cases examined here illustrate how new, relevant information can be provided when children are given a second opportunity to describe their experiences. In experimental situations, new details may be classified as inconsistencies, but such definitions have clearly led to considerable misunderstanding in applied real-world contexts. 
To appear in Psychology, Public Policy and Law (APA copyright) http://www.apa.org/pubs/journals/law/index.aspx

This article may not exactly replicate the final version published in the APA journal. It is not the copy of record.

The research on repeated interviews may also have been misinterpreted because readers have confused repeated interviewing with repeatedly asking the same questions in the same interview, or with other risky practices, including repeated suggestive questioning. For example, a recent U.S. Supreme Court case (Kennedy v. Louisiana, 2008) concerning a child victim of sexual abuse, opined "Studies conclude that children are highly susceptible to suggestive questioning techniques like repetition, guided imagery, and selective reinforcement [emphasis added]." Moreover, in a recent survey of adults, including those polled immediately after completing jury duty in the U.S. (Quas et al., 2005), 46\% agreed with the statement, "Repeatedly asking children general open-ended questions, such as 'What happened? What else happened?' often leads them into making false claims of sexual abuse," further illustrating the pervasiveness of the view that repeating questions, even nonsuggestive ones, is inherently harmful! This is of course not true.

The translation of psychological principles into practical guidelines and legal policy is complicated by the fact that investigative interviewers, their managers, and the major 'consumers' of their interviews have limited understanding of basic memory principles. This was poignantly highlighted by a [paraphrased] comment from a practitioner following presentation of these cases at a recent meeting of the International Investigative Interviewing Research Group (April, 2009): "I would have made sure to ask all the right questions in the first interview so that I would not need a second interview." Clearly, this practitioner (and perhaps others) do not understand that people of all ages routinely fail to report all 'remembered' information the first time they are asked, and that reminiscence is an extremely common and normal feature of memory (Erdelyi, 1996; Gilbert \& Fisher, 2006; La Rooy et al., 2009). These cases illustrate that one interview is often not enough, yet interviewers lack the confidence and awareness to utilize this straightforward memory-enhancing technique - 
To appear in Psychology, Public Policy and Law (APA copyright) http://www.apa.org/pubs/journals/law/index.aspx

This article may not exactly replicate the final version published in the APA journal. It is not the copy of record.

giving children another opportunity to talk. Or, they are not allowed to do so by the established rules and policies of their jurisdiction.

Whilst encouraging interviewers to capitalize on the memory-enhancing properties of repeated interviewing, we must also offer a strong note of caution. In the interviews excerpted here, open-ended questions predominated. Such prompts are crucial when facilitating reminiscence, and are also, of course, a key element of best-practice interviewing (see Lamb et al., 2008, for review). As such, particular attention should be given to the quality of initial interviews when deciding whether or not to re-interview because suggestibility can be exacerbated by repeated interviews (La Rooy et al., 2009). Interviews cannot be assumed to be of high quality just because they are conducted in jurisdictions that have adopted best-practice interview guidelines (e.g., Sternberg, Lamb, Davies, \& Westcott, 2001). Repeated interviews are most likely to be useful in jurisdictions that provide high quality training, regularly review interview quality, and emphasize continued professional development, with attention paid to fundamental memory concepts. Mandatory recording of each interview would, of course, maximise the ability to understand what happened while documenting the appropriateness of the questions asked.

\section{Implications for policy and practice}

The cases described here illustrate clearly that substantial amounts of new information can be recalled when children are re-interviewed, suggesting that the 'reminiscence' effect should perhaps be considered sufficient grounds for conducting repeated interviews.

Currently, the legal guidelines and best practices appear to recognize some psychological literature concerning repeated interviewing (e.g., on reluctance to disclose) and account for some of the reasons why children may need another opportunity to talk. However, current guidelines ignore the phenomenon of reminiscence despite well-established findings in this area. Thus, the guidelines do not account for all situations in which it may be beneficial to 
To appear in Psychology, Public Policy and Law (APA copyright) http://www.apa.org/pubs/journals/law/index.aspx

This article may not exactly replicate the final version published in the APA journal. It is not the copy of record.

interview a child more than once. In the future, researchers need to examine the effects on children's accounts when they are interviewed more than two times. More than the two repeated interviews that we studied here.

Legal cases and practical guidelines for interviewers reflect the notion that repeated interviews necessarily affect children's credibility, possibly leading fact finders to suspect that children's statements may have been contaminated following repeated interviews. However, as we have shown with these cases involving children of different ages and circumstances, repeated non-suggestive interviews should not automatically lead investigators to dismiss children's statements, and may be very valuable to investigators. The benefits were illustrated here using a relatively straightforward procedure -- constructing an interview composite -- which may be a helpful way for interviewers to demonstrate the efficacy of repeated interviews in their own work. 
To appear in Psychology, Public Policy and Law (APA copyright ) http://www.apa.org/pubs/journals/law/index.aspx

This article may not exactly replicate the final version published in the APA journal. It is not the copy of record.

References

Ackil, J., Van Abbema, D., \& Bauer, P. (2003). After the storm: Enduring differences in mother-child recollections of traumatic and nontraumatic events. Journal of Experimental Child Psychology, 84, 286-309.

Baker-Ward, L., Hess, T. M., \& Flannagan, D. A. (1990). The effects of involvement on children's memory for events. Cognitive Development, 5, 55-69.

Berliner, L., \& Conte, J.R. (1993). Sexual abuse evaluations- conceptual and empirical obstacles. Child Abuse and Neglect, 17, 111-125.

Bluck, S., Levine, L. J., \& Laulhere, T. M. (1999). Autobiographical remembering and hypermnesia: A comparison of older and younger adults. Psychology and Aging, 14, 671-682.

Bornstien, B. H., Liebel, L. M., \& Scarberry, N. C. (1998). Repeated testing in eyewitness memory: A means to improve recall of a negative emotional event. Applied Cognitive Psychology, 12, 119-131.

Brainerd, C. J., \& Ornstein, P. A. (1991). Children's memory for witnessed events: The developmental backdrop. In The suggestibility of children's recollections: Implications for eyewitness testimony, Doris J (Ed.) American Psychological Association: Washington, 10-23.

Brainerd, C.J., \& Reyna, V.F. (2005). The science of false memory. Oxford, UK: Oxford University Press.

Brainerd, C. J., Reyna, V. F., Howe, M. L., \& Kingma, J. (1990). The development of forgetting and reminiscence. Monographs of the Society for Research in Child Development, 55, (Serial No. 222). 
To appear in Psychology, Public Policy and Law (APA copyright) http://www.apa.org/pubs/journals/law/index.aspx

This article may not exactly replicate the final version published in the APA journal. It is not the copy of record.

Bruck, M., Ceci, S.J., \& Hembrooke, H. (2002). The nature of children's true and false narratives. Developmental Review, 22, 520-554.

Bruck, M., \& Ceci, S. (2004). Forensic developmental psychology-unveiling four common misconceptions. Current Directions in Psychological Science, 13, 229-232.

Bruck, M., \& Ceci, S. (2004). Forensic developmental psychology-unveiling four common misconceptions. Current Directions in Psychological Science, 13(6), 229-232.

Burgwyn-Bailes, E., Baker-Ward, L., Gordon, B. N., \& Ornstein, P. A. (2001). Children's memory for emergency medical treatment after one year: The impact of individual difference variables on recall and suggestibility. Applied Cognitive Psychology, 15, S25-S48.

Carnes, C. N., Nelson-Gardell, D., Wilson, C., \& Orgassa, U. C. (2001). Extended forensic evaluation when sexual abuse is suspected: A multisite field study. Child Maltreatment, 6, 230-242.

Carnes, C. N., Wilson, C., \& Nelson-Gardell, D. (1999). Extended forensic evaluation when sexual abuse is suspected: A model and preliminary data. Child Maltreatment, 4, 242254.

Ceci, S. J., \& Bruck, M. (1993). Suggestibility of the child witness: A historical review and synthesis. Psychological Bulletin, 113, 403-439.

Ceci, S. J., Huffman, M. L. C., Smith, E., \& Loftus, E.F. (1994). Repeatedly thinking about a non-event- source misattributions among preschoolers. Consciousness and Cognition, 3, 388-407.

Ceci, S. J., Loftus, E. F., Leichtman, M. D., \& Bruck, M. (1994). The possible role of source misattributions in the creation of false beliefs among preschoolers. International Journal of Clinical and Experimental Hypnosis, 42, 304-320. 
To appear in Psychology, Public Policy and Law (APA copyright ) http://www.apa.org/pubs/journals/law/index.aspx

This article may not exactly replicate the final version published in the APA journal. It is not the copy of record.

Ceci,S. J., Kulkofsky, S, Klemfuss, J. Z., Sweeney, C. D., Bruck, M. (2007). Unwarranted Assumptions about Children's Testimonial Accuracy. Annual Review of Clinical Psychology, 3, 311-328.

Commonwealth v. Baran, 905 N. E. 2d 1122 (Mass. Ct. App. 2009).

Cordon, I. M., Pipe, M.-E., Sayfan, L., Melinder, A., \& Goodman, G. S. (2004). Memory for traumatic experiences in early childhood. Developmental Review, 24, 101-132.

Dale, P.S., Loftus, E.F., \& Rathbun, L. (1978). The influence of the form of the question on the eyewitness testimony of preschool children. Journal of Psycholinguistic Research, 7, 269-277.

Dent, H.R. (1986). An experimental study of the effectiveness of different techniques of questioning mentally-handicapped child witnesses. British Journal of Clinical Psychology, 25, 13-17.

Dent, H.R. \& Stephenson, G.M. (1979). An experimental study of the effectiveness of different techniques of questioning child witnesses. British Journal of Social and Clinical Psychology, 18, 41-51.

Dunning, D., \& Stern, L. B. (1992). Examining the generality of eyewitness hypermnesia: A close look at time delay and question type. Applied Cognitive Psychology, 6, 643-657.

Erdelyi, M. H. (1996). The Recovery of Unconscious Memories: Hypermnesia and Reminiscence. Chicago: University of Chicago Press.

Erdelyi, M. H., \& Becker, J. (1974). Hypermnesia for pictures: Incremental memory for pictures but not words in multiple recall trials. Cognitive Psychology, 6, 159-171.

Fivush, R., Hamond, N.R., Harsch, N., (1991). Content and consistency in young children's autobiographical recall. Discourse Processes, 14,, 373-388. 
To appear in Psychology, Public Policy and Law (APA copyright) http://www.apa.org/pubs/journals/law/index.aspx

This article may not exactly replicate the final version published in the APA journal. It is not the copy of record.

Fivush, R., McDermott Sales, J., Goldberg, A., Bahrick, L., \& Parker, J. (2004). Weathering the storm: Children's long-term recall of Hurricane Andrew. Memory, 12, 104-118.

Fivush, R., \& Schwarzmueller, A. (1995). Say it once again: Effects of repeated questions on children's event recall. Journal of Traumatic Stress, $\underline{8}, 555-580$.

Fivush, R., \& Shukat, J. (1995). What young children recall: issues of content, consistency and coherence of early autobiographical recall. In M.S. Zaragoza, J.R. Graham, G.C.N. Hall, R. Hirchman \& Y.S. Ben-Porath (Eds.), Memory and Testimony in the child witness (pp. 5-23). Thousand Oaks, CA: Sage.

Ghetti, S., Goodman, G.S., Eisen, M.L., Qin, J., \& Davis, S.L. (2002). Consistency in children's reports of sexual and physical abuse. Child Abuse and Neglect, 26, 977995.

Gilbert, J. A. E., \& Fisher, R. P. (2006). The effects of varied retrieval cues on reminiscence in eyewitness memory. Applied Cognitive Psychology, 20, 723-739.

Gobbo, C. (2000). Assessing the effects of misinformation on children's recall: How and when makes a difference. Applied Cognitive Psychology, 14, 163-182.

Goodman, G.S., Bottoms, B.L., Schwartz-Kenney, B.M., \& Rudy, L. (1991). Children`s testimony about a stressful event: improving children's reports. Journal of Narrative and life history, 1, 69-99.

Goodman, G. S., Hirschman, J. E., Hepps, D., \& Rudy, L. (1991). Children's memory for stressful events. Merrill-Palmer Quarterly, 37, 109-158.

Goodman, G.S., \& Quas, J.A. (2008). Repeated interviews and children's memory: it's more than just how many. Current Directions in Psychological Science, 17, 386-390. 
To appear in Psychology, Public Policy and Law (APA copyright) http://www.apa.org/pubs/journals/law/index.aspx

This article may not exactly replicate the final version published in the APA journal. It is not the copy of record.

Goodman, G.S., Taub, E.P., Jones, D.P.H., England, P., Port, L.K., Rudy, L., \& Prado, L.

(1992). Testifying in criminal court: Emotional effects on child sexual assault victims. Monographs of the Society for Research in Child Development, 57, 1-142.

Gordon, B.N., Baker-Ward, L., \& Ornstein, P.A. (2001). Children's testimony: A review of research on memory for past experiences. Clinical Child and Family Psychology Review, 4, 157-181.

Gordon, B., \& Follmer, A. (1994). Developmental issues in judging the credibility of children's testimony. Journal of Clinical Child Psychology, 23, 283-294.

Hamond, N.R., \& Fivush, R. (1991). Memories of Mickey Mouse- young children recount their trip to Disneyworld. Cognitive Development, 6, 433-448.

Hershkowitz, I., Horowitz, D., \& Lamb, M.E. (2005). Trends in children's disclosure of abuse in Israel: A national study. Child Abuse and Neglect, 29, 1203-1214.

Herskowitz, I., Orbach, Y., Lamb, M. E., Sternberg, K. J., Horowitz, D., \& Hovav, M. (1998). Visiting the scene of the crime: Effects on children's recall of alleged abuse. Legal and Criminological Psychology, 3, 195-207

Hershkowitz, I., \& Terner, A. (2007). The effects of repeated interviewing on children's forensic statements of sexual abuse. Applied Cognitive Psychology, 21, 1131-1143.

Home Office. (2007). Achieving Best Evidence in Criminal Proceedings: Guidance on Interviewing Victims and Witnesses, and Using Special Measures. London: Author.

Howe, M. L., \& Brainerd, C. J. (1989). Development of children's long-term retention. Developmental Review, 9, 301-340.

Howe, M. L., Kelland, A., Bryant-Brown, L., \& Clark, S. L. (1992). Measuring the development of children's amnesia and hypermnesia. In M. L. Howe, C. J. Brainerd 
To appear in Psychology, Public Policy and Law (APA copyright) http://www.apa.org/pubs/journals/law/index.aspx

This article may not exactly replicate the final version published in the APA journal. It is not the copy of record.

and V. F. Reyna (Eds), Development of Long-Term Retention (pp. 56-102). New

York: Springer-Verlag.

Hutcheson, G.D., Baxter, J.S., Telfer, K., \& Warden, D. (1995). Child witness statement quality: question type and error of omission. Law and Human Behavior, 19, 631-648.

Katz, C., \& Hershkowitz, I. (under review). The effect repeated open questions on children's accounts of sexual abuse. Law and Human Behavior.

Kennedy v. Louisiana, _ U.S. _, 128 S. Ct. 2641, 171 L. Ed. 2d 525 (2008).

Lamb, M. E., \& Fauchier, A. (2001). The effects of question type on self contradiction by children in the course of forensic interviews. Applied Cognitive Psychology, 15, 1-9.

Lamb, M. E., Hershkowitz, I., Orbach, Y. \& Esplin, P. W. (2008). Tell me what happened. Chichester, UK and Hoboken, NJ: Wiley.

Lamb, M. E., Orbach, Y., Hershkowitz, I., Esplin, P. W., \& Horowitz, D. (2007). A structured forensic interview protocol improves the quality and the informativeness of investigative interviews with children: A review of research using the NICHD investigative interview Protocol. Child Abuse and Neglect, 31, 1201-1231.

Lamb, M. E., Orbach, Y., Hershkowitz, I., Horowitz, D., \& Abbott, C .B. (2007). Does the type of prompt affect the accuracy of information provided by alleged victims of abuse in forensic interviews? Applied Cognitive Psychology, 21, 1117-1130.

La Rooy, D., Lamb, M. E., \& Pipe, M-E. (2009). Repeated Interviewing: A critical evaluation of the risks and potential benefits. In K. Kuehnle \& M. Connell (Eds.) The Evaluation of Child Sexual Abuse Allegations: A Comprehensive Guide to Assessment and Testimony (pp. 327-361). Hoboken NJ: Wiley.

La Rooy, D., Pipe, M.-E., \& Murray, J. E. (2005). Reminiscence and hypermnesia in children's eyewitness memory. Journal of Experimental Child Psychology, 90, 235254. 
To appear in Psychology, Public Policy and Law (APA copyright) http://www.apa.org/pubs/journals/law/index.aspx

This article may not exactly replicate the final version published in the APA journal. It is not the copy of record.

La Rooy, D., Pipe, M.-E., \& Murray, J. E. (2007). Enhancing children's event recall after long delays. Applied Cognitive Psychology, 21, 1-17.

Law Commission. (1997). The evidence of children and other vulnerable witnesses.

Wellington, NZ: Author.

Leichtman, M. D., \& Ceci, S. J. (1995). The effects of stereotypes and suggestions on preschoolers' reports. Developmental Psychology, 31, 568-578.

Leippe, M.R., Romanczyk, A., \& Manion, A.P. (1992). Eyewitness persuasion: How and how well do fact finders judge the accuracy of adults and children's memory reports. Journal of Personality and Social Psychology, 63, 181-197.

Malloy, L.C., Lyon, T.D., Quas, J.A. (2007). Filial dependency and recantation of child sexual abuse allegations. Journal of the American Academy of Child and Adolescent Psychiatry, 46, 162-170.

Malloy, L.C., \& Quas, J.A. (2009). Children's suggestibility: Areas of consensus and controversy. In K. Kuehnle \& M. Connell (Eds.), The evaluation of child sexual abuse allegations: A comprehensive guide to assessment and testimony. Hoboken, $\mathrm{NJ}$ : Wiley.

Melnyk, L., \& Bruck, M. (2004). Timing moderates the effects of repeated suggestive interviewing on children's eyewitness memory. Applied Cognitive Psychology, 18, $613-631$.

Merritt, K. A., Ornstein, P. A., \& Spicker, B. (1994). Children's memory for a salient medical procedure: Implications for testimony. Pediatrics, 94, 12-23. 
To appear in Psychology, Public Policy and Law (APA copyright) http://www.apa.org/pubs/journals/law/index.aspx

This article may not exactly replicate the final version published in the APA journal. It is not the copy of record.

Orbach, Y., Hershkowitz, I., Lamb, M.E., Sternberg, K.J., Esplin, P.W., \& Horowitz, D. (2000). Assessing the value of structured protocols for forensic interviews of alleged child abuse victims. Child Abuse and Neglect, 24, 733-752.

Orbach, Y. \& Lamb, M.E. (2001). The relationship between within-interview contradictions and eliciting interview utterances. Child Abuse and Neglect, 25, 323-333.

Ornstein, P.A. (1995). Children's long term retention of salient personal experiences. Journal of Traumatic Stress, 8, 581-605.

Ornstein, P.A., Baker-Ward, L., Gordon, B.N., \& Merritt, K.A. (1997). Children`s memory for medical experiences: implications for testimony. Applied Cognitive Psychology, $11,87-104$.

Ornstein, P. A., Baker-Ward, L., Gordon, B. N., Pelphrey, K. A. Staneck Tyler, C., \& Gramzow, E. (2006). The influence of prior knowledge and repeated questioning on children's long-term retention of the details of a paediatric examination. Developmental Psychology, 42, 332-344.

Ornstein, P.A., Gordon, B.N., \& Larus, D.M. (1992). Children's memory for a personally experienced event- implications for testimony. Applied Cognitive Psychology, 6, 4960.

Payne, D. G. (1987). Hypermnesia and reminiscence in recall: A historical and empirical review. Psychological Bulletin, 101, 5-27.

Peterson, C., Moores, L., \& White, G. (2001). Recounting the same events again and again: Children's consistency across multiple interviews. Applied Cognitive Psychology, 15, 353-371. 
To appear in Psychology, Public Policy and Law (APA copyright) http://www.apa.org/pubs/journals/law/index.aspx

This article may not exactly replicate the final version published in the APA journal. It is not the copy of record.

Peterson, C. (1996). The preschool child witness: Errors in accounts of traumatic injury. Canadian Journal of Behavioural Science, 28, 36-42.

Peterson, C. (1999). Children's memory for medical emergencies: 2 years later. Developmental Psychology, 35, 1493-1506.

Peterson, C., \& Bell, M. (1996). Children's memory for traumatic injury. Child Development, 67, 3045-3070. Peterson, C., Pardy, L., Tizzard-Drover, T., \& Warren, K. L. (2005). When initial interviews are delayed a year: Effect on children's 2-year recall. Law and Human Behavior, 29, 527-541.

Peterson, C., \& Whalen, N. (2001). Five years later: Children's memory for medical emergencies. Applied Cognitive Psychology, 15, S7-S24.

Pipe, M.-E., Gee, S., Wilson, J. C., \& Egerton, J. M. (1999). Children's recall 1 or 2 years after an event._Developmental Psychology, 35, 781-789.

Pipe, M.E., Lamb, M.E., Orbach, Y., \& Cederborg, A.C., (Eds.), (2007). Child sexual abuse: Disclosure, delay, and denial. Mahwah, NJ: Erlbaum.

Pipe, M.-E., Lamb, M. E., Orbach, Y., \& Esplin, P. W. (2004). Recent research on children's testimony about experienced and witnessed events. Developmental Review, 24, 440468.

Pipe, M.-E., Sutherland, R., Webster, N., Jones, C. H., \& La Rooy, D. (2004). Do early interviews affect children's long-term recall? Applied Cognitive Psychology, 18, 117.

Pipe, M-E., Gee, S., Wilson, J.C., \& Egerton, J. M. (1999). Children's recall 1 or 2 years after an event. Developmental Psychology, 35, 781-789. 
To appear in Psychology, Public Policy and Law (APA copyright) http://www.apa.org/pubs/journals/law/index.aspx

This article may not exactly replicate the final version published in the APA journal. It is not the copy of record.

Plotnikoff, J., \& Woolfson, R. ( 2001). An evaluation of child witness support. Scottish

Executive Central Research Unit. Report available from:

http://www.scotland.gov.uk/cru/kd01/purple/witness01.pdf

Poole, D. A., \& White, L. T. (1993). Two years later: Effects of question repetition and retention interval on the eyewitness testimony of children and adults. Developmental Psychology, 29,, 844-853.

Powell, M. B., Jones, C. H., \& Campbell, C. (2003). A comparison of preschoolers' recall of experienced versus non-experienced events across multiple interviews. Applied Cognitive Psychology, 17, 935-952.

Powell, M. B., \& Thomson, D. M. (1997). The effect of an intervening interview on children's ability to remember one occurrence of a repeated event. Legal and Criminological Psychology, 2, 247-262.

Principe, G. F., \& Ceci, S. J. (2002). "I saw it with my own ears": The effects of peer conversations on preschoolers reports of nonexperienced events. Journal of Experimental Child Psychology, 83, 1-25.

Quas, J.A., Goodman, G.S., Bidrose, S., Pipe, M.E., Craw, S., \& Ablin, D.S. (1999). Emotion and memory: children`s long-term remembering, forgetting and suggestibility. Journal of Experimental Child Psychology, 72, 235-270.

Quas, J.A., Malloy, L.C., Melinder, A., Goodman, G.S., D`Mello, M., Schaaf, J. (2007). Developmental differences in the effects of repeated interviews and interviewer bias on young children's event memory and false reports. Developmental Psychology, 43, 823-837.

Quas, J.A., Thompson, W.C., Clarke-Stewart, K.A. (2005). Do jurors “know” what isn't so about child witnesses? Law and Human Behavior, 29, 425-456. 
To appear in Psychology, Public Policy and Law (APA copyright) http://www.apa.org/pubs/journals/law/index.aspx

This article may not exactly replicate the final version published in the APA journal. It is not the copy of record.

Raskin, D.C., \& Esplin, P.W. (1991). Statement validity assessment- interview procedures and content-analysis of children's statements of sexual abuse. Behavioural Assessment, 13, 265-291.

Roediger, H. L. III, Payne, D. G., Gillespie, G. L., \& Lean, D. S. (1982). Hypermnesia as determined by level of recall. Journal of Verbal Learning and Verbal Behavior, 21, 635-655.

Roediger, H. L. III, \& Karpicke, J. D. (2006). The power of testing memory basic research and implications for educational practice. Perspectives on Psychological Science, 1, 181-210.

Salmon, K., \& Pipe, M-E. (1997). Props and children's event reports: The impact of a 1-year delay. Journal of Experimental Child Psychology, 65, 261-292.

Salmon, K., \& Pipe, M-E. (2000). Recalling an event one year later: The impact of props, drawing and a prior interview. Applied Cognitive Psychology, 14, 99-120.

Scottish Executive. (2003). Guidance Interviewing Child Witnesses and Victims in Scotland. Edinburgh: Author.

Scottish Executive. (2007). On the record: Evaluating the visual recording of joint investigative interviews with children. Edinburgh: Author.

Scrivner, E., \& Safer, M. A. (1988). Eyewitnesses show hypermnesia for details about a violent event. Journal of Applied Psychology, 73, 371-377.

Shapiro, S. R., \& Erdelyi, M. H. (1974). Hypermnesia for pictures but not words. Journal of Experimental Psychology, 103, 1218-1219.

State v. Bobadilla, 709 N. W. 2d 243 (Minn. 2006).

Sternberg, K.J., Lamb, M.E., Davies, G.M., \& Westcott, H.L. (2001). The memorandum of good practice: theory versus application. Child Abuse and Neglect 25, 669-681. 
Steward, M. S., Steward, D. S., Farquhar L., Myers, J. E. B., Reinhart, M., Welker J., Joyce, N., Driskill, J., \& Morgan, J. (1996). Interviewing young children about body touch and handling. Monographs of the Society for Research in Child Development, 57, (Serial No. 248). 
Table 1

Composite of repeated interviews with a 14-year-old girl describing several episodes of abuse

First incident

It started when I was about eleven, going on twelve. He was downstairs with my mum and then he came up to tuck us in like he usually does. It was night time. We were both in our beds. He was in my room and he was having a long chat with us. My sister fell asleep and then he took me into a different room. He asked me to go to the other room with him. Then he started talking to me. It started from there. He started feeling me. He touched my fanny (vagina) with his hands. He got his finger and he rubbed it round my fanny. It was under my clothes. I had my nightie on. He had clothes on.

\section{$\underline{\text { Last incident: }}$}

It was in the evening. My mum had gone out. My brother was in his room asleep and my sister was in her room asleep. It was upstairs in my room. It was the room I've got now. It was my mum's room ${ }^{1}$. I think he told me to 'get on the bed,' so I did and then he started touching me again, and he tried to put his willy inside me, but he couldn't. He touched me with his hands and his willy. He put his hands on my fanny and in my fanny. He put his fingers inside me. He held it with his hands and then he rubbed it up me near my fanny. Around it and on it. He made me touch him around his willy. He told me to. He made me pull his willy up and down. It was all floppy and then it had an erection. He held it with his hands.

\footnotetext{
${ }^{1}$ The child means that the room she has now was formally her mother's room.
} 
I think I was on the bed and then he got on top of me. He tried to put it inside me but he couldn't. His willy was too big.

$\underline{\text { Incident involving watching a pornographic video }}$

It was downstairs. I was doing my homework or something. He put a video on and told me I had to watch it. He made me watch a video. He sat with me and we watched the video. It had people on it showing sex and things like that. Having sex. They had them (their clothes) off. The willy was going into the fanny. Then it finished and I went to bed.

\section{Incident with making a pornographic video:}

One day he brought a video camera home which one of his mates had let him borrow. It was a school day. Then later on my mum had to go out. She was going to her meditation group. There was me, my sister and my brother and $M$ (alleged perp.) We made the video of all of us. We had our tea and then the other two went to bed. He said he was going to make a video. It was upstairs in the bedroom that was my mum's. He switched the video camera on and he then put it on the table. It (the video camera) was on a table. The bed was there. The table was in the corner next to the window. He told me to take my clothes off so I did. He said to 'get on the bed,' so I did. He had no clothes on either, he took his clothes off. He told me to pull his willy up and down. He held it with his hand. It was near my fanny. The front bit. It went near the hole. He tried to put his willy inside me again. It hurt. He was on top of me. And then he made a video of me. We got our clothes on. He took it (the video camera). He just put it in a bag that it was supposed to go in. I think it had letters like Adidas or something like that. I think it was red and black. I've got the case for it. He forgot to take it (ha). 
Table 2

Composite of repeated interviews with a reluctant 6-year-old girl

The first and second time:

The same thing happened but in our old house. Sometimes he showed me his penis and sometimes he put his penis inside but he always stopped when they (my parents) came home. But sometimes if daddy was not home and mum was with the baby he would touch me.

The last time:

It happened at night. Mummy and daddy were not at home, I told him I needed to go to the toilet. He said it was ok and when I came back he asked me to give him a kiss and a hug and so I did. When he finished his computer game, he asked me if I wanted him to lie next to me. I told him that I did. He got into bed and covered us both. He took off my trousers and underwear although I told him not to. He took off some of his underwear and then he put his penis into my vagina. He used his hand to hold his penis and it was very hard and painful and then I felt water from his penis flowing into my bottom. I told him "no, please", but he kept saying "Please, one more minute", so I counted to 60, because I had been told that was a minute, but then he told me "another minute", so I counted again and again. And then he asked me to see a movie with him. I agreed and then he told me to go to sleep because our parents had arrived, so I went to sleep but when my mummy came into the room I asked her if I could come and talk to you. 
Table 3

Composite of repeated interviews with a 13-year-old girl who discussed the same episode of abuse in both interviews

A month ago, on Saturday, I was playing in the street. It was dark and no one was in the

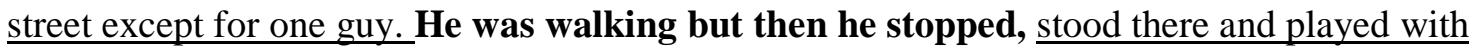
his hair. He was looking at me. Then he continued walking. I didn't see him. Suddenly I saw him in the entrance of my building. Then he came to me and asked if the x family lived there. I didn't see him so well so I came closer and told him I don't know, with my head. Either I told him or I shook my head, I don't remember. And then he pulled me and grabbed me in my vagina and bottom and my whole body shivered. I saw him start playing with his fingers making all kinds of strange shapes. And then he got closer and knocked me into the mailboxes. I was far from the mailboxes so he caught my body like this (demonstration) and threw me toward the mailboxes. $\underline{\text { He grabbed me in my private }}$ place; it was hard and very painful. I was very afraid and didn't understand what he wanted and I was also disgusted by the smell of alcohol in his breath. Then he lifted me, with two fingers in my private place, I felt unbearable pain, like this with my legs in the air. And then he pushed two of his fingers into my vagina and two in my bottom. He did both at the

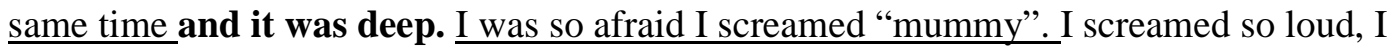
didn't know how that I could scream that loud. Then he said "ok ok bye" and ran away. Then I was so afraid I ran home immediately. 
Table 4

Composite of repeated interviews with a 5-year-old boy who discussed the same episode of abuse in both interviews

Yesterday he met me outside my house. So no one would see us, he asked me to come with him to his secret place. We were in his secret place, I told him that I did not want to come with him, but he begged so I agreed, because I didn't want him to get upset with me because he is bigger than me. He is 9 years old. And then he started. He took off his trousers and underwear and I took off mine. He covered me with something. First I sucked his penis. The smell from his penis was terrible and that is why I threw up and then he sucked

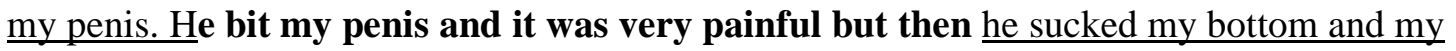
breast and then it was no longer so bad and then I sucked his penis again and then he sucked

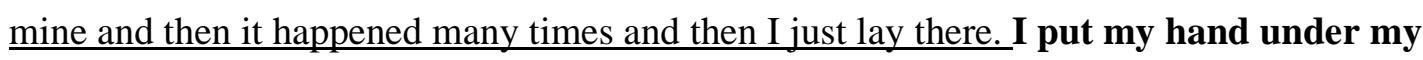
head so it would not be painful and then he did a poo. He walked away but then took some leaves and put the poo on it and then he took his poo and rubbed his poo on me, here (demonstrating). I was lying there and did not feel very good and then he sucked my penis. I $\underline{\text { was vomiting but he kept sucking my penis. He did it many times. After he sucked my penis }}$ he licked my breast and bottom. And then I put my clothes on. All my clothes had his poo on and he told me, "don`t tell anyone." 